\title{
Speciation needs in relation with environmental and biological purposes
}

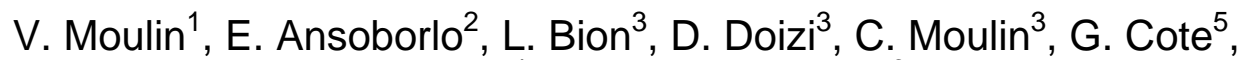 \\ C. Madic ${ }^{4}$ and J. Van der Lee ${ }^{6}$ \\ ${ }^{1}$ CEA, Nuclear Energy Division (DEN)/DDIN, CEA-Saclay, 91191 Gif-sur-Yvette, France \\ ${ }^{2} C E A$-Valrho/DEN/DRCP, ${ }^{3} C E A$-Saclay/DEN/DPC, ${ }^{4} C E A$-Saclay/DEN, ${ }^{5} E N S C P$-University \\ Pierre \& Marie Curie, Paris, ${ }^{6} E M P / C I G$, Fontainebleau, France
}

\begin{abstract}
Radionuclides can occur in the environment either through chronic releases of nuclear facilities, or due to incidents or accidents. In order to study there behaviors in the environment (migration, retention, transfer, ...) and in human organisms (metabolism, retention, excretion), it is of prime importance to know their solution chemistry, and more particularly thermodynamic equilibrium constants, allowing to calculate their speciation. In fact, speciation governs the migration, the bioavailability and the toxicity of elements. Moreover, this knowledge is also of great interest for decorporation or decontamination purposes. In this framework, a CEA working group on speciation has been created in order to share data both on thermodynamic constants and on analytical speciation methods, interesting chemists, environmentalists and biologists. It has been focused, in a first time, on actinides and a choice of specific ligands considered to be most representative of environmental and biological media. The thermodynamic database used is BASSIST (developed by CEA) in interaction with the speciation model JCHESS. Different examples are then presented on the selection of data (thermodynamic constants, ligands of interest) through benchmark exercises to test our state of knowledge in this area. Also, analytical methods to determine thermodynamic constants or direct speciation are discussed.
\end{abstract}

\section{INTRODUCTION}

The determination of speciation constitutes a key issue to explain and evaluate the mobility, the toxicity and the risk resulting from the presence of trace elements in ecosystems [1-4]. It contributes to a better understanding of their fate (retention, transport, bioavailability) in these systems up to human organisms. In particular, the case of radionuclides is of prime importance in the context of environment and waste management purposes, notably in case of chronic, incidental or accidental release from nuclear facilities. Moreover, for human beings, in case of internal contamination with radionuclides under acute or chronic mode, radiological and chemical toxicity can be induced after different biological steps dominated by kinetics but also related to the speciation of the species.

Therefore the knowledge of speciation is essential for understanding and interpreting the mechanisms involved in the reactivity of elements either in environmental or biological media, and also for scaling associated experiments.

Hence, the objective of this paper is to recall some fundamental principles relative to speciation (definition, determination) and to present the scope of research of a CEA working group on speciation by illustrating some significant needs in terms of actinide speciation in relation with environmental and biological purposes. 


\section{SPECIATION: DEFINITION AND DETERMINATION}

\subsection{Definition}

Determining the speciation of an element in a particular medium implies to identify, characterize and quantify the different physicochemical forms of that element. This involves defining the chemical form (oxidation state, charge, proportion and nature of the complexed forms) and sometimes the physical form (distribution among soluble, colloidal or particulate forms, and solid phases, modes of association and physical localization) in which it occurs.

Two definitions are used in the fields of chemistry and biology, respectively: i) chemical speciation which is static, describes the operational process of identification and quantification of a chemical species containing a particular element, ii) biological speciation, which is a more dynamic concept, concerns the conversion of one species into another through a dynamic reaction process. Recent guidelines for terms related to chemical speciation and fractionation of elements have been published as IUPAC recommendations [5], including definitions, structural aspects and methodological approaches.

\subsection{Determination of speciation}

Speciation can be determined essentially by two ways, either by calculating the distribution of chemical forms from thermodynamic stability constants that describe the chemical equilibria involved, or by direct or indirect analytical methods.

\subsubsection{The calculation approach}

This approach requires the knowledge of the composition of the medium, in particular in terms of complexing agents, and the physicochemical equilibrium involved along with the associated thermodynamic constants. This allows to calculate:

- in solution, the solubility and distribution of the different complexed forms in the given medium, the medium being completely defined by its composition, i.e., $\mathrm{pH}$, redox potential $(E h)$, ionic strength, concentrations of cations and anions with identification of ligands and complexing agents (inorganic, organic and biological compounds),

- $\quad$ in a solid-solution system, the distribution of the element between liquid and solid phases considering the presence of colloids and particles, of solid substrates (mineral surfaces, biological interfaces, etc.). In this case are needed either the corresponding thermodynamic surface constants (ion exchange or surface complexation constants) of the species formed at the solid surfaces, or a distribution coefficient $(\mathrm{Kd})$, if physico-chemical conditions are identical in the Kd determination and the speciation conditions.

Hence, having a thermodynamic data base (solubility products, stability constants), speciation calculations can be performed in the liquid phase, and in the same manner in the presence of a solid phase with an appropriate data base (distribution coefficients, ion exchange constants or surface complexation constants). That means that these values are either known and validated (reference values) or unknown, implying their determination through the development or application of appropriate analytical techniques.

Speciation diagrams are usually generated with the aid of computing methods, for example calculation codes (JCHESS [6]), which also allows to take into account precipitation, colloid formation and redox potentials. An example of the prediction of cobalt speciation in a biological medium, given in Figure 1, shows the influence of the composition of the medium depending on whether organic complexing agents such as citrate ions are taken into account or not. 


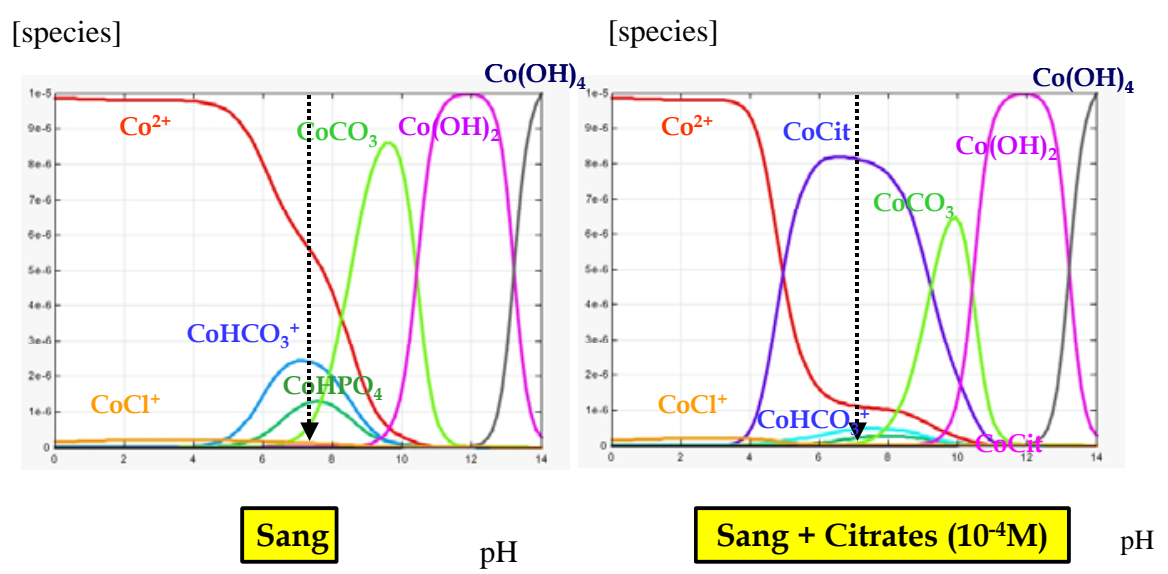

Figure 1. Calculated speciation of cobalt at a concentration of $10 \mu \mathrm{M}$ in blood without citrates (left) and with a $10^{-4} \mathrm{M}$ solution of citrates (right). The composition of the medium is given in Table 1.

\subsubsection{The analytical approach}

Two main categories of analytical methods may be distinguished: direct and indirect methods.

The determination of speciation via direct analytical methods such as those of laser spectrometry (fluorescence, photoacoustic, etc.) and mass spectrometry, which allow to work directly on a sample, has been developed thanks to the increasing performances of analytical tools. Given the complexity of the biological and environmental media, it is recommended to first study simple systems: a single ligand, for example, representative of the media of interest, and supported by a facility offering an array of spectroscopic methods to gain access to complementary data and also to cross-check pre-existing information. After validation of the tools on these simple systems, application to complex media can be considered.

Indirect methods rely on the use of separative methods (dialysis, ultrafiltration, chromatography, electrophoresis, resins) and detection of one or several elements (atomic absorption, inductively coupled plasma with atomic emission spectroscopy (AES) or mass spectrometry (MS) detection, radiochemical or electrochemical methods).

Here are presented some methods used without exhaustiveness and the information they can provide (see reference [7-12] for more details):

- Nuclear magnetic resonance (NMR) [up to $10^{-4} \mathrm{M}$ ] supplies information on the structure and stoichiometry of complexes, and allows the determination of complexation constants.

- Extended X-ray absorption fine structure (EXAFS) [up to $10^{-4} \mathrm{M}$ ] enables to study the chemical environment of an element and obtain data such as oxidation state, coordination, type, number and distances of neighboring atoms.

- Electrospray mass spectrometry (ES-MS) [up to $10^{-6} \mathrm{M}$ ] allows to characterize and to quantify chemical species. Using this method it is possible to gain direct access to the speciation and thereby measure complexation constants, and also to the isotopic composition.

- Time-Resolved Laser Induced Fluorescence (TRLIF) [up to $10^{-8} \mathrm{M}$ in speciation mode, and valid for fluorescent elements such as U (VI), Cm (III) and most of lanthanides] allows to characterize species and to determine complexation constants and co-ordination numbers. 
- High performance liquid chromatography or capillary electrophoresis coupled with inductively coupled plasma mass spectrometry (HPLC/ICP-MS) allows for separation and speciation at very low concentrations, thanks to ICP-MS detection, and isotopic determination. Experimental CE/ICP-MS coupling has determined speciation at concentration levels as low as $10^{-12} \mathrm{M}$.

- Radiochemical and chemical separations provide the redox speciation of elements (for example, the distribution of oxidation states of plutonium in natural media such as oceans, lakes and rivers) at very low concentrations (down to $10^{-16} \mathrm{M}$ ). These methods mainly involve solvent extraction, co-precipitation and separation on resins.

The use of these different methods, in addition to the structural and chemical data obtained, also offers the possibility of working in a wide range of concentrations $\left(10^{-12} \mathrm{M}\right.$ to $\left.0.1 \mathrm{M}\right)$. Thus the availability of a panel of methods allows to determine the speciation of an element, and in particular the stoichiometry and complexation constant(s) of the element with the ligand(s) studied. Furthermore, combining several methods enables to crosscheck and to validate results.

Obviously, the results derived from the use of these methods are meaningful only if the samples studied, whether synthetic or naturally-occurring, are handled and conserved under conditions that preserve their representativity (for example, maintenance of redox state by working in a glove box under a controlled atmosphere).

\subsection{Towards the creation of a working group}

The development at CEA of studies related to human nuclear toxicology and decorporation procedures, and to biogeochemical cycles and decontamination processes (Environmental Nuclear Toxicology Programme [13]) has pointed out the need of speciation knowledge for understanding and interpreting the mechanisms involved in the reactivity of elements, and also for scaling associated experiments (predictive calculations). Other programmes also mention this need [14], as well as UNSCEAR committee on radioecology [15].

A CEA working group on speciation [GT32 within CETAMA (CEA/DEN/DRCP)] has then been created in order to share data both on thermodynamic constants and on analytical speciation methods, of interest for chemists, environmentalists and biologists, and focusing, in a first time, on the actinides, namely Th, U, Pu, Am and Np.

On the one hand, its objective is to implement a database developed at CEA with data relevant to biological and environmental media. This chemical thermodynamic database is named BASSIST (Base Applied to Speciation in Solution at Interfaces and SolubiliTy) and contains equilibrium constants involving actinides, fission products, activation products [16]. The development of the BASSIST database corresponds to i) the integration of international certified values, such as data from OCDE/NEA review (for elements such as Pu, Am, Np, U, Tc) [17], ii) the addition of other selected data from international literature (mainly PSI [18] and IUPAC [19] databases) and iii) the addition of data obtained from chemical analogies between elements such as, for example, between the lanthanides and trivalent actinides. One major point of this database is the association to each value of an indicator of reliability and robustness, through data compilation and critical analysis.

On the other hand, its objective is also to give and share analytical speciation methodologies for the above-mentioned scopes of research. Benchmark exercises constitute also a major activity in this working group.

Table 1 gives an example of some thermodynamic constants implemented in BASSIST. 
Table 1. Decimal logarithm of stability constants of some aqueous inorganic and organic actinide complexes at zero ionic strength with their reliability indicator (IR) (IR varying from 3 (good) to 0 (bad)). The uncertainties on values are not reported here in the table.

\begin{tabular}{|c|c|c|c|c|}
\hline & $\mathbf{U}$ & Np & Pu & Am \\
\hline Oxidation state & $\mathrm{U}(\mathrm{VI})$ as $\mathrm{UO}_{2}{ }^{2+}$ & $\mathrm{Np}(\mathrm{V})$ as $\mathrm{NpO}_{2}^{+}$ & $\mathrm{Pu}(\mathrm{IV})$ as $\mathrm{Pu}^{4+}$ & $\mathrm{Am}(\mathrm{III})$ as $\mathrm{Am}^{3+}$ \\
\hline in biological fluids & Yes & Yes with Np(IV) & Yes & yes \\
\hline in environmental solutions* & $\mathrm{O}$ & $\mathrm{O} / \mathrm{R}$ & $\mathrm{O} / \mathrm{R}$ & $\mathrm{O} / \mathrm{R}$ \\
\hline Ionic radius (A) & 0.83 & 0.88 & 0.90 & 0.99 \\
\hline \multicolumn{5}{|l|}{$\log \beta_{\imath}(\mathrm{I}=0)$} \\
\hline Hydroxide $^{\S}$ & $\begin{array}{c}\beta_{1}=-5.2(\mathrm{IR}=3) \\
\beta_{2}=-10.3(\mathrm{IR}=1) \\
\beta_{3}=-19.2(\mathrm{IR}=3) \\
\beta_{4}=-33(\mathrm{IR}=3)\end{array}$ & $\begin{array}{l}\beta_{1}=-11.3(\mathrm{IR}=3) \\
\beta_{2}=-23.6(\mathrm{IR}=3)\end{array}$ & $\begin{array}{c}\beta_{1}=-0.78(\mathrm{IR}=3) \\
\beta_{2}=-2.0(\mathrm{IR}=1) \\
\beta_{3}=-5.0(\mathrm{IR}=1) \\
\beta_{4}=-7.5(\mathrm{IR}=2)\end{array}$ & $\begin{array}{c}\beta_{1}=-6.4(\mathrm{IR}=3) \\
\beta_{2}=-14.1(\mathrm{IR}=3) \\
\beta_{3}=-25.7(\mathrm{IR}=3) \\
\beta_{4}=-40.05(\mathrm{IR}=2)\end{array}$ \\
\hline Carbonate $\left(\mathrm{CO}_{3}{ }^{=}\right)^{\S}$ & $\begin{array}{c}\beta_{1}=9.68(\mathrm{IR}=3) \\
\beta_{2}=16.94(\mathrm{IR}=3) \\
\beta_{3}=21.6(\mathrm{IR}=3)\end{array}$ & $\begin{array}{c}\beta_{1}=4.96(\mathrm{IR}=3) \\
\beta_{2}=6.53(\mathrm{IR}=3) \\
\beta_{3}=5.5(\mathrm{IR}=3)\end{array}$ & $\begin{array}{l}\beta_{4}=35.9(\mathrm{IR}=3) \\
\beta_{5}=34.5(\mathrm{IR}=3)\end{array}$ & $\begin{array}{c}\beta_{1}=7.8(\mathrm{IR}=3) \\
\beta_{2}=12.3(\mathrm{IR}=3) \\
\beta_{3}=15.2(\mathrm{IR}=3)\end{array}$ \\
\hline \begin{tabular}{|l|} 
Phosphate \\
$\left(\mathrm{PO}_{4}^{3-}\right)$
\end{tabular} & $\beta_{1}=13.23(\mathrm{IR}=3)$ & & & \\
\hline$\left(\mathrm{HPO}_{4}{ }^{\prime}\right)$ & $\beta_{1}=7.24(\mathrm{IR}=3)$ & $\beta_{1}=2.95(\mathrm{IR}=3)$ & $\begin{array}{c}\beta_{1}=12.9(\mathrm{IR}=1) \\
\beta_{2}=23.7(\mathrm{IR}=1) \\
\beta_{3}=33.4(\mathrm{IR}=1) \\
\beta_{4}=43.2(\mathrm{IR}=1) \\
\beta_{5}=52(\mathrm{IR}=1)\end{array}$ & \\
\hline$\left(\mathrm{H}_{2} \mathrm{PO}_{4}^{-}\right)$ & $\begin{array}{l}\beta_{1}=1.12(\mathrm{IR}=3) \\
\beta_{2}=0.64(\mathrm{IR}=3)\end{array}$ & & & 3.0 \\
\hline$\left(\mathrm{H}_{3} \mathrm{PO}_{4}\right)$ & $\beta_{1}=0.76(\mathrm{IR}=3)$ & & $\beta_{1}=2.4(\mathrm{IR}=3)$ & \\
\hline Citrate $\left(\mathrm{L}^{3-}\right)$ & $\begin{array}{c}\beta_{1}=8.69(\mathrm{IR}=2) \\
\beta_{2}=19.51(\mathrm{IR}=2)\end{array}$ & $\beta_{1}=3.74(\mathrm{IR}=2)$ & $\begin{array}{l}\beta_{1}=15.2(\mathrm{IR}=2) \\
\beta_{2}=30.1(\mathrm{IR}=2)\end{array}$ & $\begin{array}{c}\beta_{1}=8.67(\mathrm{IR}=2) \\
\beta_{2}=20.22(\mathrm{IR}=2)\end{array}$ \\
\hline
\end{tabular}

${ }^{*} \mathrm{O}=$ oxic $\mathrm{R}=$ reducing conditions $\S$ no polynuclear are listed here.

\section{SOME RESULTS}

In the framework of biogeochemical studies, questions arise concerning the physico-chemical form of a trace element before incorporation/ingestion/transfer towards a living organism, the form of the element in the organism, the transport mechanism, ... which are directly linked to their speciation. From a general point of view, this is of prime importance, notably in relation with environmental impact assessments [20]. Hence in the framework of our studies, the main media of interest will be soils and waters in contact with biosphere (human and non-human biota). Table 2 gives several compositions (without exhaustiveness in terms of species) of biological and environmental fluids.

The aim of this paragraph is to illustrate the application and utility of a database such as BASSIST in order to predict or explain the presence of species in a specific medium by using a speciation code like JCHESS [6] as well as to underline needs in thermodynamic data. Benchmark speciation exercises have been performed and some major conclusions are here presented, in particular in the case of actinides $\mathrm{Am}, \mathrm{Pu}, \mathrm{Np}, \mathrm{U}$. The oxidation states chosen for these elements are respectively III, IV, V and VI as the predominant oxidation state prevailing in biological/environmental (mainly oxic conditions) media. 
Speciation calculations have been realized by varying $\mathrm{pH}$ (2-12) taking or not into account precipitation (then by varying actinide concentration) with a specific interest for the blood conditions with presence of citrate, phosphate and carbonate ligands. These ligands are also relevant for environmental media (rhizosphere, surface or subsurface conditions) such as soil solutions, root exudates,....

Table 2. Composition of some biological (blood) and environmental (surface water, soil solution) fluids without exhaustiveness.

\begin{tabular}{|l|c|c|c|}
\hline & Blood & Surface waters [21] & Soil solutions [22] \\
\hline $\mathrm{pH}$ & 7.4 & $6.5-8.5$ & $4-8.5$ \\
\hline Species & & & \\
\hline $\mathrm{Ca}^{2+}$ & $1.4 \mathrm{mM}$ & $0.4 \mathrm{mM}$ & \\
\hline $\mathrm{K}^{+}$ & $0.5 \mathrm{mM}$ & & \\
\hline $\mathrm{Mg}^{2+}$ & $0.6 \mathrm{mM}$ & $0.2 \mathrm{mM}$ & \\
\hline $\mathrm{Na}^{+}$ & $0.09 \mathrm{M}$ & $0.25 \mathrm{mM}$ & \\
\hline $\mathrm{Fe}$ & $0.3 \mu \mathrm{M}$ & & \\
\hline $\mathrm{H}_{4} \mathrm{SiO}_{4}$ & & $0.2 \mathrm{mM}$ & \\
\hline $\mathrm{Cl}^{-}$ & $0.09 \mathrm{M}$ & $0.2 \mathrm{mM}$ & \\
\hline $\mathrm{PO}_{4}{ }^{+}$ & $1.1 \mathrm{mM}$ & & \\
\hline $\mathrm{SO}_{4}{ }^{-}$ & $0.33 \mathrm{mM}$ & & \\
\hline $\mathrm{HCO}_{3}{ }^{-}$ & & $0.001 \mathrm{M}$ & \\
\hline $\mathrm{CO}_{3}{ }^{-}$ & $0.025 \mathrm{M}$ & & $1-160 \mathrm{mM}$ \\
\hline DOC* & & $0.1-5 \mathrm{mM}$ & $1-400 \mu \mathrm{M}$ \\
\hline Citrate & $0.16 \mathrm{mM}$ & & \\
\hline Lactate & $1.5 \mathrm{mM}$ & & $1-600 \mu \mathrm{M}$ \\
\hline Oxalate & $9.2 \mu \mathrm{M}$ & & \\
\hline Albumin & $0.63 \mathrm{mM}$ & & \\
\hline Transferrin & $37 \mu \mathrm{M}$ & & \\
\hline
\end{tabular}

*DOC $=$ dissolved organic carbon which includes low molecular weight organic acids and also humic substances (humic/fulvic acids).

In a general way, one point has to be mentioned which is common for all elements. According to the database used, organic ligands may be present or not as ligands. For example they are completely absent of the NEA database whatever the type of organics. Moreover depending on the nature of the organics (simple molecules like low molecular weight organic acids such as acetic acid, citric acid, oxalic acid, ..., amino acids or more complex ones such as proteins like albumin, transferrin, ..., humic substances such as humic or fulvic acids), thermodynamic data could be missing. It is the particular case of complex organic molecules (proteins, humic substances) for which, respectively, either data do not exist, or coherent and homogeneous systems including binding models and data are missing. Hence, BASSIST has been implemented with thermodynamic data relative to citrate complexes of $\mathrm{Am}(\mathrm{III}), \mathrm{Pu}(\mathrm{IV}), \mathrm{Np}(\mathrm{V}), \mathrm{U}(\mathrm{VI})$ from the literature. In the case of $\mathrm{U}(\mathrm{VI})$-citrate complexes, some discrepancies between thermodynamic data are noticed.

An important point to underline concerns the values of auxiliary data (acidity constants for example of inorganic/organic acids): necessity to know this value to recalculate the constants in another system (for example with HL instead of $\mathrm{L}$ if $\mathrm{L}$ is the deprotonated form of the ligand).

Moreover, the inorganic speciation of all actinides studied is relatively well documented through the impressive work of the OCDE/NEA [17] and PSI [18], except in the case of the phosphate ligands. For example, for Am(III), the role of phosphate solids controlling the solubility of Am(III) has been emphasized, namely the role of $\mathrm{AmPO}_{4}$, present or not in various databases, in particular the absence of $\Delta \mathrm{G}$ corresponding to the formation of this solid, in the NEA database. Hence, the impact of thermodynamic database used on speciation results may be important in terms of species prediction (for scaling or interpreting experiments). These and other consequences on future behavior in a particular medium are detailed elsewhere [23]. 
For Pu(IV), large discrepancies exist for the thermodynamic constants related to phosphate-Pu system as well as for the complex stoichiometries $\left(\mathrm{Pu}\left(\mathrm{H}_{\mathrm{x}} \mathrm{PO}_{4}\right)_{\mathrm{y}}{ }^{\mathrm{z}}\right)$. For $\mathrm{U}(\mathrm{VI})$, some discrepancies among the data related to the phosphate system exist. It can be also mentioned that for Pu(IV), uncertified data are existing for the species $\mathrm{Pu}(\mathrm{OH})_{4}$ [18]. The absence of data in the NEA database implies a non-correct predominance of the species $\mathrm{Pu}(\mathrm{OH})^{3+}$ in solution.

As concerns the role of the different ligands upon actinide speciation, several situations are occurring. In the case of Am(III), the role of organic ligands such as citrate ions is underlined. Their presence significantly modifies Am speciation, in particular in the acidic-neutral $\mathrm{pH}$ range $(5<\mathrm{pH}<7)$, where Am-citrate complexes entirely dominate instead of free Am and carbonate complexes. For higher $\mathrm{pH}$, carbonate complexes are present.

For Pu(IV) in the presence of citrate ligands, organic complexes predominate up to $\mathrm{pH} 10$. For higher $\mathrm{pH}$ hydroxide species are present. If formation of solids is enabled, then $\mathrm{PuO}_{2}$ controls the system.

For $\mathrm{Np}(\mathrm{V})$, the influence of the thermodynamic constant related to the formation of the Np-citrate complex through a sensibility study has been pinpointed. In the absence of organic ligands, $\mathrm{Np}(\mathrm{V})$ speciation in the medium studied is mainly dominated by carbonate ligand in the neutrality $\mathrm{pH}$ range, whereas as expected only $\mathrm{NpO}_{2}{ }^{+}$exists in the acidic $\mathrm{pH}$ range. Under alkaline conditions, the presence of mixed species (hydroxo-carbonate) dominates. For $\mathrm{Np}(\mathrm{V})$, the role of phosphate ligands is negligible due to the weak value of the corresponding stability constant.

For U(VI) the complexation by citrate ions induces the presence of organic complexes in the acidic $\mathrm{pH}$ range (4-6). According to the type of citrate complex stoichiometry this $\mathrm{pH}$ range may be increased. For higher $\mathrm{pH}$ carbonate complexes are dominating.

Hence these results concerning specific radionuclides and ligands illustrate the need to complete the databases (thermodynamic constants) in order to be able to predict their speciation firstly in simple systems. Analytical tools should then be used to determine missing values. Table 3 summarizes some of these techniques previously mentioned which could be used in the CEA working group for benchmarking exercises on analytical speciation.

Table 3. Potentialities of different analytical tools.

\begin{tabular}{|l|c|c|c|c|c|}
\cline { 2 - 5 } \multicolumn{1}{c|}{} & $\begin{array}{c}\text { Oxidation } \\
\text { State }\end{array}$ & $\begin{array}{c}\text { Chemical } \\
\text { species }\end{array}$ & $\begin{array}{c}\text { Quantitative } \\
\text { analysis }\end{array}$ & Sensitivity & $\begin{array}{c}\text { In situ } \\
\text { analysis }\end{array}$ \\
\hline $\begin{array}{l}\text { Spectrophotometry (SP) or } \\
\text { TL* or LIPAS** }\end{array}$ & +++ & + & + & + & no \\
\hline $\begin{array}{l}\text { Time-Resolved laser Induced } \\
\text { Fluorescence (TRLIF) }\end{array}$ & $(+)$ & + & + & +++ & yes \\
\hline $\begin{array}{l}\text { Electrospray Mass } \\
\text { Spectrometry (ES-MS) }\end{array}$ & + & + & + & ++ & no \\
\hline
\end{tabular}

*thermal lensing; **laser induced photoacoustic spectroscopy.

\section{CONCLUSION}

In various environments, radionuclide speciation may completely differ from one system to another, since various ligands can complex these trace elements leading to the formation of different species. This repartition of species may be either determined, or predicted by calculations with help of stability constants. The reliability of these constants and the robustness of the methods to measure them are of key importance to accurately establish the speciation. Speciation will then affect the fate of a toxic element (predicted through modeling) in the geosphere and the biosphere, as well as the behavior of such element in a given experiment (use of predicted speciation for further investigations). Moreover, developments in analytical methods (and in particular spectrometric techniques) offer now the possibility to directly determine the speciation of the element of interest, under conditions relevant to natural systems. Since speciation constitutes a key factor in the behavior and repartition of elements in aquatic and terrestrial systems as well as in trace element bioavailability, its determination and prediction is of prime importance. 
It is important to underline that there are some missing stability constants in thermodynamic databases either because values are not existing (for example, sugar family, amino-acids, proteins, chelating agents, exopolymers ...), or because coherent binding models integrating all metals (case of humic substances) are lacking. Investigations in the field of inorganic speciation are also needed (case of phosphate, silicate systems, and also case of fission/activation products).

The CEA working group will aim at providing and expertizing new data to implement the database BASSIST, which could be then selected as a data base in a speciation code (like JCHESS), or used in the CTDP project [24]. This is also performed in collaboration and interaction with the Risk Control Domain (CEA) and the Environmental Nuclear Toxicology research program developed by CEA with CNRS, Inserm and Inra.

\section{Acknowledgments}

The authors are grateful to all GT32 participants for useful discussions during meetings and participations in benchmark exercises.

\section{References}

[1] Tessier A. and Turner D.R., Metal speciation and bioavailability in aquatic systems (John Wiley and Sons, 1995)

[2] Contamination des sols par les éléments en traces : les risques et leur gestion. Rapport $N^{\circ} 42$ (Août 1998). Académie des Sciences (Lavoisier TECDOC)

[3] Moulin V. and Moulin C., Radiochim. Acta. 89 (2001) 773-778.

[4] Ansoborlo E., Chiappini R. and Moulin V., Clefs CEA 48 (2003) 14-18.

[5] Templeton D.M., Freek A., Cornelis R., Danielsson L., Muntau H., van Leeuwen H. and Lobinski R. Pure Appl. Chem 72 (2000) 1453-1470

[6] Van Der Lee J., CHESS software (2002).

[7] OECD Proceedings of the Workshop on "Evaluation of Speciation Technology" held in Japan/October 1999. Code 662001041P1 OECD May 2001

[8] Moulin C., Radiochim. Acta 91 (2003) 651-658.

[9] Special Issue Speciation: Databases and Analytical Methods, Radiochim. Acta 91 (2003).

[10] Lobinski R., Applied Spectr. 51 (1997) 260A-278A.

[11] Kobashi A., Choppin G.R. and Morse J.W., Radiochim. Acta, 43 (1988) 211-215.

[12] Cornelis R., Caruso J., Crews H. and Heumann K. Handbook of elemental speciation: techniques and methodology, Wiley (2003).

[13] Leguay J.J., Clefs CEA 48 (2003) 107-108.

[14] Barescut J.C., Environnement, Risques \& Santé 3 (2004) 173-177.

[15] UNSCEAR 2003-2006 «De l'expostion aux rayonnements ionisants aux effets sur la santé », Colloque 15 juin 2004.

[16] Bion L., Radiochim. Acta 91 (2003) 633-638.

[17] http://www.nea.fr/html/dbtdb.

[18] Hummel W., Berner U., Curti E., Pearson F.J. and Thoenen T. Nagra/PSI, Chemical thermodynamic Data base 01/01 (2002).

[19] SC-Database, Royal Society of Chemistry, http://www.acadsoft.co.uk/, IUPAC (2004)

[20] Salbu B., Lind O.C. and Skipperrud L., J. Environ. Radioactivity 74 (2004) 233-242.

[21] Sigg L, Stumm W and Behra P. Chimie des milieux aquatiques, Masson ( 1992).

[22] Strobel B.W., Geoderma 99 (2001) 169-198.

[23] Bion L. et al., under preparation

[24] Lomenech C. and Van der Lee J. Radiochim. Acta in print. 